Bull. Mater. Sci., Vol. 21, No. 2. Aptil 1998, pp. 107-110. C Indian Academy of Sciences.

\title{
Crystalline alumina films prepared by nebulized spray pyrolysis
}

\author{
P MURUGAVEL, BENEDICT ITA ${ }^{\dagger}$ and A R RAJU* \\ Chemistry and Physics of Materials Unit, Jawaharlal Nehru Centre for Advanced Scientific Research, \\ Bangaiore 560 064, India \\ ${ }^{\dagger}$ Chemistry Departraent, University of Calabar, Calabar, Nigeria
}

MS received 20 January 1998

\begin{abstract}
Crystalline aluming films have been successfully deposited on Si(100) and amorphous stlica substrates by the nebulized spray pyrolysis technique. The surface morphology of the films has been studied by various microseopic techniques. The films exhibit satisfactory microhardness and frequency independent capacitance.
\end{abstract}

Keywords. Crystalline alumina; nebulized spray pyrolysis; SEM; AFM; mierohard̆ness.

\section{Introduction}

Alumina films are of considerable interest because of their potential applications for wear resistant coatings and optical coatings. Amorphous alumina thin films have been prepared on glass as well as $\mathrm{Si}(100)$ by chemical vapour deposition from aluminum acetylacetonate (Maruyama and Arai 1992). Metal organic chemical vapour deposition by using precursors such as aluminium tris-dipivaloylmethanate (Kin et al 1993; Ciliberto et al 1995), also yields amorphous films on silicon and glass substrates. Single crystalline gamma alumina films have been grown on stlicon substrates by metalorganic molecular beam epitaxy using aluminum alkoxide (lizuka et al 1992), while heteroepitaxial gamma alumina films are obtained with trimethyl aluminum (Istida et al 1988). CVD of alumina on silicon substrates by using aluminum trichloride gives films of $\mathrm{K}-\mathrm{Al}_{7} \mathrm{O}_{3}$ which transforms to $\alpha-\mathrm{Al}_{2} \mathrm{O}_{3}$ on being heated to higher temperatures of $1200-1350 \mathrm{~K}$ (Fredriksson and Carlsson 1993). By ionbeam-induced chemical vapour deposition, trimethyl aluminum gives crystalline $\mathrm{o}-\mathrm{Al}_{2} \mathrm{O}_{3}$ films at $1273 \mathrm{~K}$ (Caballero et al 1996). We were interested in exploring whether crystalline alumina films could be obtained by employing the simple technique of nebulized spray pytolysis.

\section{Experimental}

The technique of nebulized spray pyrolysis for depositing thin films by employing a home built apparatus has beet described elsewhere (Raju et al 1995; Ajyer et al 1997). The apparatus consists of two zones: (i) the atomization chamber and (ii) the pyrolysis reactor. The source liquid is kept in the atomization chamber which is attached

\footnotetext{
*Author for correspondence
}

with a PZT transducer at the bottom which oscillates at a frequency of $1.72 \mathrm{MHz}$. Aluminium acetylacetonate in a methanol solvent $(0.05 \mathrm{M})$ was employed for all the depositions. When a high-frequency ultrasonic beam is directed at the liquid/gas interface, a geyser forms at the surface of the liquid and the height of the geyser is proportional to the acoustic intensity and the physical properties of the liquid (vapour pressute, viscosity and surface tension). When the amplitude of the acoustic vibrations exceeds a certain threshold value, atomization of the liquid occurs. Above this threshold, a continuous and regular mist is generated. The mist is carried by the carrier gas (dry air in the present case) to the pyrolysis reactor zone onto a pre-heated substrate leading to the mist decomposition and the film formation on the substrate. We have used single crystal $\mathrm{Si}(100)$ as well as polished amorphous silica as the substrates in the present study.

Alumila films were characterized by $X$-ray diffraction, scanning electron microscopy (SEM), electron difftaction, atomic force microscopy (AFM), capacitance measurements and dynamic hardness measurements. A Seifert $3000 \mathrm{X}$-ray powder diffractometer with $\mathrm{Cu}-\mathrm{K} \alpha$ radiation (grazing incident geometry) was employed for X-ray diffraction studies. A Leica S440i SEM was used for microstructure studies. Nanoscope II fitted with AFM was used to study the surfaces of the films at highresolution. Capacitance and tan $\delta$ were measured between $100 \mathrm{~Hz}$ and $10 \mathrm{MHz}$ with $\mathrm{HP} 4296$ automatic impedance analyser. Shimadzu dynamic ultra microhardness irstrument (DUH 200) was employed to study microhardness of the films. The method of measuring hardness using nano indentation involves making small indentation using Berkovich indentor, while continuously recording the indentation load, $P(g f)$ and displacement, $h(\mu \mathrm{m})$ during one complete cycle of loading and unloading. The $\mathrm{DH}=\alpha P / h^{2}$, where $\alpha$ is a constanl 
in accordance with the shape of the indentor (indentation factor).
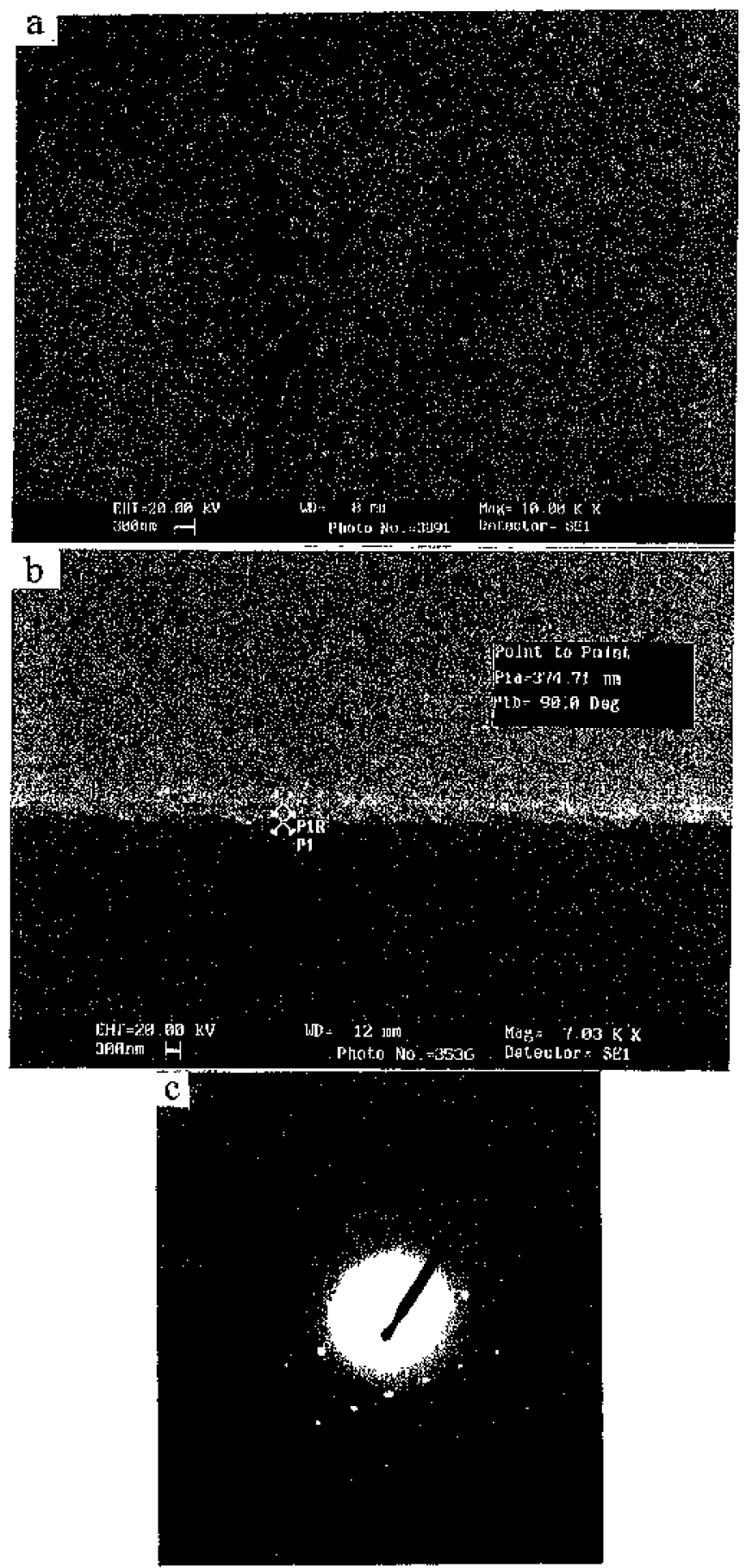

Figure 1. a. Scaming electron micrograph of an $\mathrm{Al}_{2} \mathrm{O}_{3}$ film deposited on $S i(100)$, b. cross sectional SEM micrograph of the $\mathrm{Al}_{2} \mathrm{O}_{3}$ film deposited on $\mathrm{Si}(100$ ) (film thickness is $350 \mathrm{~nm}$ ) and $c$. electron diffiaction pattern from the peeled portion of the $\mathrm{Al}_{2} \mathrm{O}_{3}$ film deposited al $673 \mathrm{~K}$ on $\mathrm{Si}(100)$ and annealed at $973 \mathrm{~K}$ for $12 \mathrm{~h}$

\section{Results and discussion}

We have examined morphology of the $\mathrm{Al}_{3} \mathrm{O}_{3}$ films deposited at $673 \mathrm{~K}$ on $\mathrm{Si}(100)$ substrales by both SEM and AFM. We show the SEM image in figure $1 \mathrm{a}$ and a surface plot from AFM in figure 2a. The surface of the film is quite smooth, consisting of very small wellconnected grains of less than $100 \mathrm{~nm}$ size, as seen from the AFM surface plot. The surface toughness measured from the AFM surface plot is around $5.75 \mathrm{~mm}$. The thickness of $\mathrm{Al}_{2} \mathrm{O}_{3}$ film on the. $\mathrm{Si}(100)$ substrate as obtained from the cross sectional SEM image shown in figure $1 \mathrm{~b}$ is around $375 \mathrm{~nm}$.

The SEM image of an alumina film deposited on amorphous silica at $673 \mathrm{~K}$ is shown in figure $3 \mathrm{a}$. The high-resolution AFM surface plot, given in figure $2 b$ shows the presence of smaller grains $(<50 \mathrm{~nm})$. These grains are significantly smaller than those in case of $\mathrm{Al}_{2} \mathrm{O}_{3}$ films deposited on $\mathrm{Si}(100)$ substrates. The suriace roughness measured from the AFM surface plot is around $7.13 \mathrm{~mm}$. The thickness of alumina film on amorphous

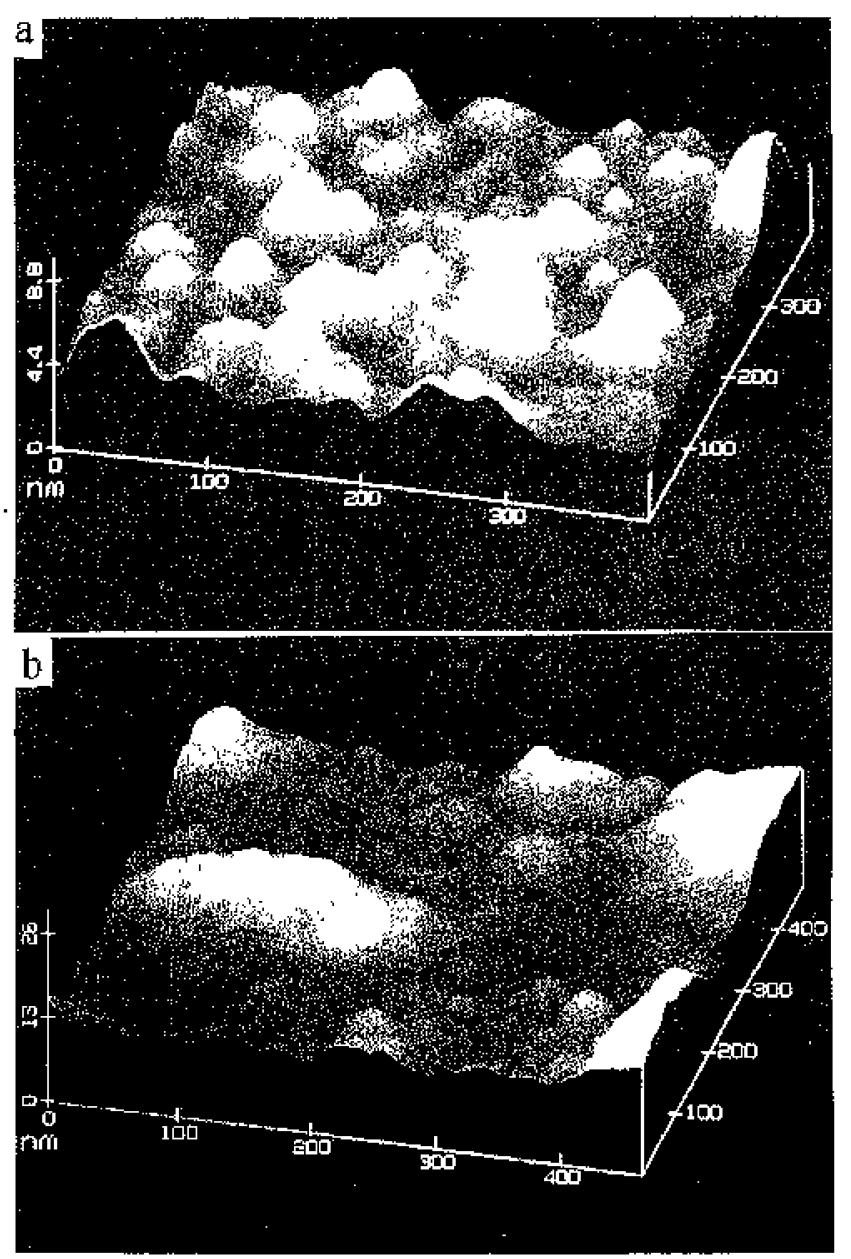

Figure 2. AFM surface plot of an $\mathrm{A}_{2} \mathrm{O}_{3}$ film deposited on a. Si(100) and b. amorphous silica. 
silica substrate is around $753 \mathrm{~nm}$ as delineated from the cross sectional SEM image in figure $3 b$.

The as-grown alumina films on both $\mathrm{Si}(100)$ and amorphous silica substrates were amorphous. After heating the film deposited on silica at $973 \mathrm{~K}$ for $12 \mathrm{~h}$, we obtained the $X$-ray diffraction paltern shown in figure 4. The pattern corresponding to the k-phase. We did not see any reflections in the $\mathrm{X}$-ray diffraction pattern of the alumina films deposited on $\mathrm{Si}(100)$ substrates at $673 \mathrm{~K}$ since the films were very thin. The electron. diffraction pattern (figure 1c) of a peeled portion of the annealed alumina film however revealed alumina was in the k-phase.

In figure 5 we show the variation of dielectric pcoperties with frequency ( $100 \mathrm{~Hz}-5 \mathrm{MHz}$ ) of $\mathrm{Al}_{2} \mathrm{O}_{3}$ films on $\mathrm{Si}(100)$ as well as $\mathrm{SiO}_{2}$ substratcs. There is only little vatiation in the capacitance with frequency, whereas the $\tan \delta$ increase at higher lrequency in the case of the film on $\mathrm{Si}$ and decreases with frequency in the film on $\mathrm{SiO}_{2}$.

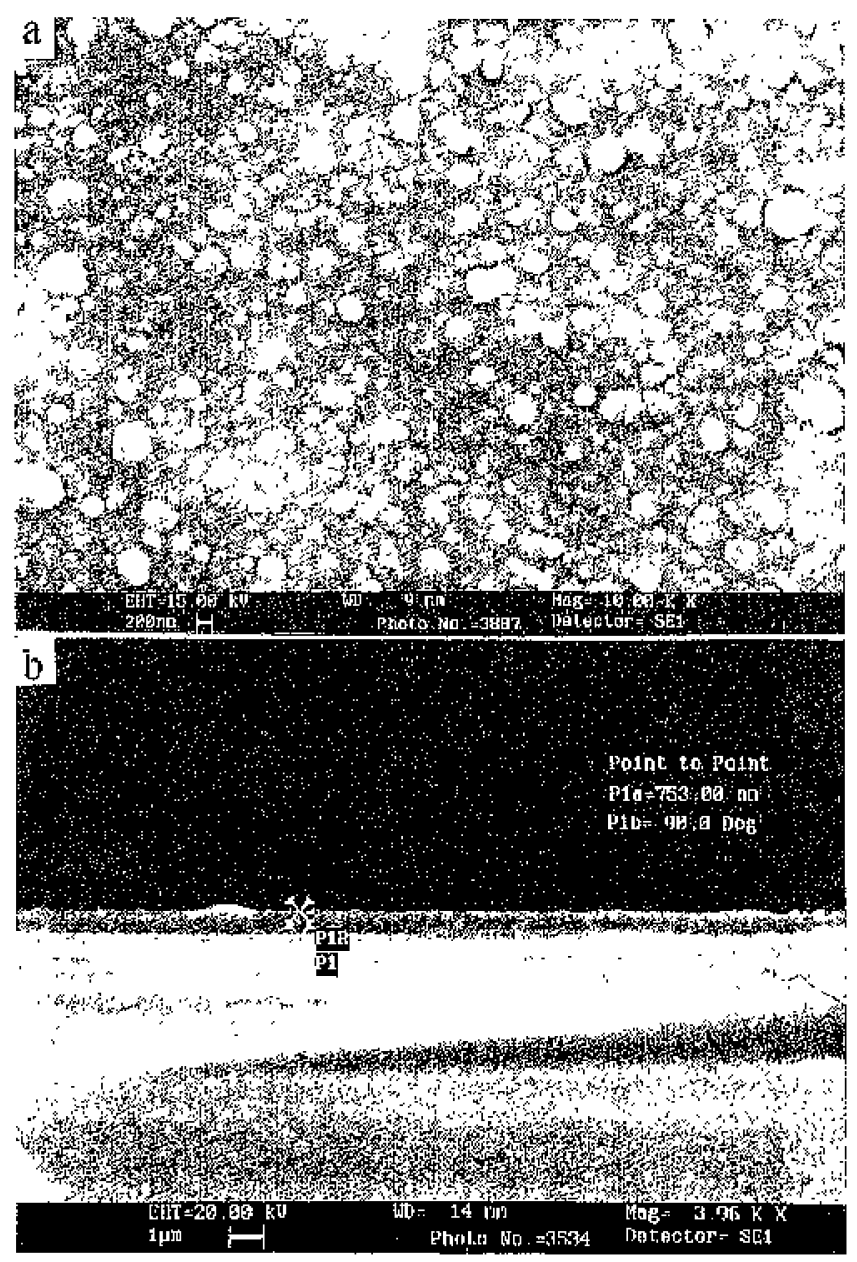

Figure 3. a. Scanning clectron micrograph of an $\mathrm{Al}_{2} \mathrm{O}_{3}$ film deposited on amorphous silica and b. cross-sectional SEM micrograph of the $\mathrm{Al}_{2} \mathrm{O}_{3}$ film deposited on amorphous silica (film thickness is $650 \mathrm{~nm}$ ).
We have measured the dynamic microhardness of the alumina films deposited on Si(100) and amorphous silica substrate with a $50 \mathrm{mg}$ load applied over $10 \mathrm{sec}$. We obtained a hardness value as high as 2010 in dynamic hardness unit (DHU) and an average of 1330 DHU from 10 measurements on different areas of the alumina film deposited on $\mathrm{Si}(100)$ substrate. However, the maximum hardness value of the film deposited on amorphous silica substrate was $2610 \mathrm{DHU}$ with an average value of 1655 DHU from 10 measurements.

\section{Conclusions}

We have deposited alumina films on Si(to0) as well as

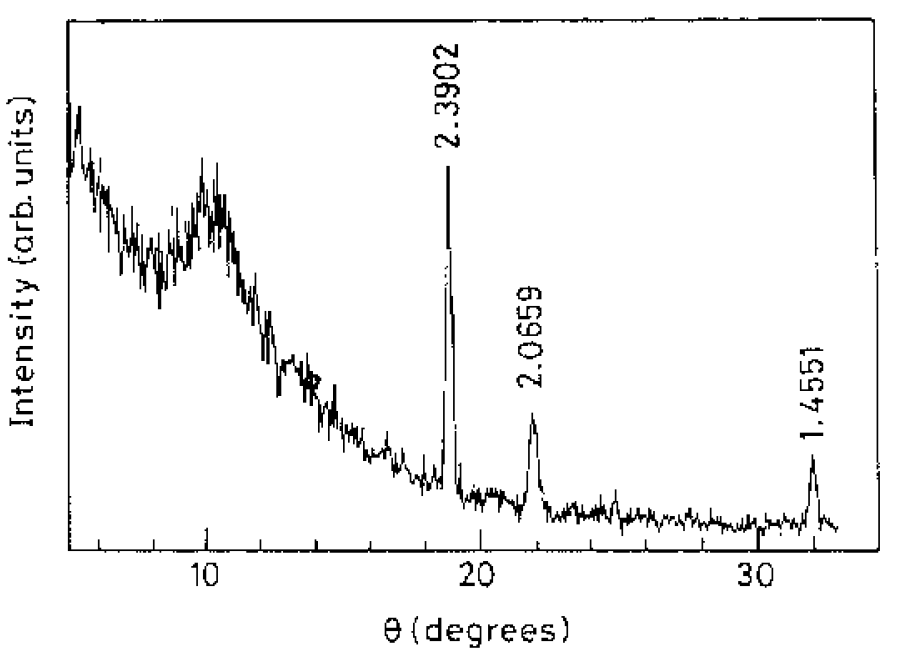

Figure 4. X-ray diffaction pattem $(\theta-\theta$ scan $)$ of an $\mathrm{Al}_{2} \mathrm{O}_{3}$ Tilin deposited at $673 \mathrm{~K}$ on amorphous silica substrate and annealed at $973 \mathrm{~K}$ lor $12 \mathrm{~h}$.

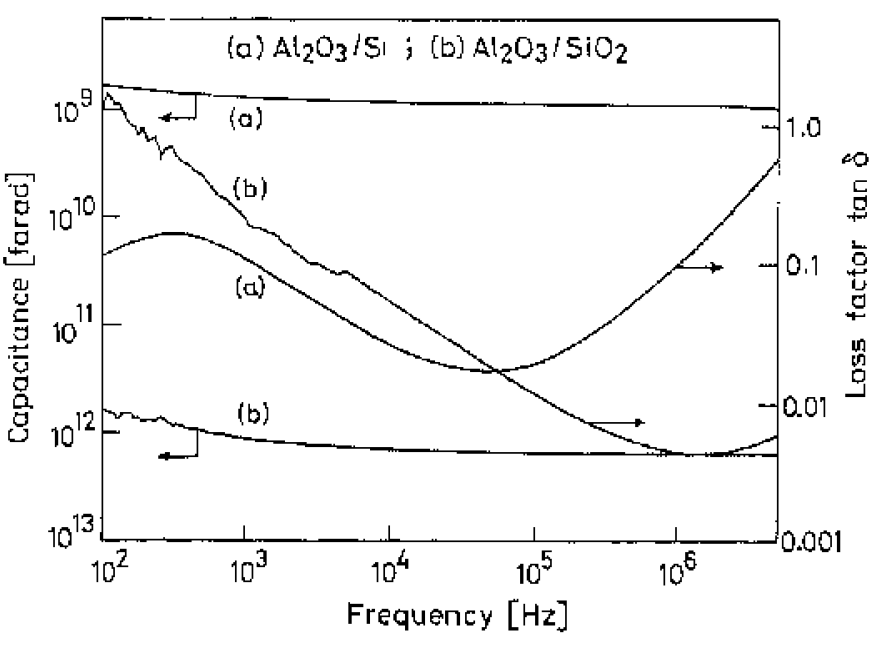

Figure 5. Capacitance and loss tactor (tan 5 ) vs lrequency of $\mathrm{Al}_{2} \mathrm{O}_{3}$ film deposited on $\mathrm{Si}(100)$ as well as $\mathrm{SiO}_{2}$ subsitates. 
$\mathrm{SiO}_{2}$ substrates by nebulized spray pyrolysis using aluminium acetylacetonate as the precursor. The asdeposited films are amorphous and crystallize to $\mathrm{k}$ alumina after annealing the films at $973 \mathrm{~K}$ for $12 \mathrm{~h}$. Dielectric measurements show variation of the capacitance with frequency in the films to be small, suggesting that they may be useful for high frequency capacitor appljcations. The average dynamic microhardness of the filtns deposited on $\mathrm{Si}(100)$ and $\mathrm{SiO}_{2}$ is substantial.

\section{Acknowledgement}

The authors thank Prof. C N R Rao for suggesting the problem, useful discussions and advice.

\section{References}

Aiyer H N, Raju A R and Rao C N R 1997 Chem. Mat. 9755 Caballero $A$, Leninen D, Fernandez $A$ and Gonzalez-Elipe A R 1996 Stuf. \& Coat, Technol. 8023

Ciliberto E, Fragala I, Rizza R and Spoto G 1995 Appl. Phys. Lett. 671624

Fredriksson E and Carisson J o 1993 Surf. Coat. Technol. 56155

lizuka H, Yokoo K and Ono S 1992 Appl. Phys, Leth. 612978 Ishida M, Katakabe I, Nakamura T" and Ohtake N 1988 Appl. Phys. Let. 521326

Kim J S, Marzouk H A, Reucroft P J, Robertson J D and Hamrin C E 1993 Appl. Phys. Lett 62 681

Martyama T and Arai S 1992 Appl Pltys. Lett. 60322

Raju A R, Aiyer H N and Rao C N R 1995 Chem. Mat 7 225 